\title{
AMPUTATION FOR PERIPHERAL VASCULAR DISEASE IN THE PARAPLEGIC AND TETRAPLEGIC
}

By D. J. Grundy, M.B., F.R.C.S. ${ }^{1,3}$ and J. R. Silver, M.B., B.S., F.R.C.P. (Ed. \& Lond.) $)^{2}$

${ }^{1}$ Registrar, ${ }^{2}$ Consultant, National Spinal Injuries Centre, Stoke Mandeville Hospital, Aylesbury, Bucks. HP2 I 8 AL. ${ }^{3}$ Now Senior Registrar, The Midland Spinal Injuries Unit, The Robert fones $\mathcal{E}$ Agnes Hunt Orthopaedic Hospital, Oswestry, Shropshire $S Y_{I O} 7 A G$.

Summary. The occurrence of lower limb gangrene due to atherosclerosis is reported in I4 spinal cord paralysed patients. A further three patients became paraplegic and developed lower limb gangrene following aortic surgery for atherosclerotic complications. The clinical features are described and the difficulty in diagnosing ischaemia in the paralysed limb is emphasised. The incidence and prognosis following amputation are similar to those in the general population and there is no evidence from this series that paraplegia and tetraplegia predispose to atherosclerosis.

Key words: Paraplegia; Tetraplegia; Atherosclerosis; Amputation.

\section{Introduction}

THE improved life expectancy of paraplegics and tetraplegics over the last $30-40$ years has resulted in an increasingly ageing patient population, with the consequence that atherosclerosis and its complications are now not uncommonly seen. Patients undergoing major lower limb amputation for gangrene due to atherosclerosis are the subject of this study.

\section{Patients and Methods}

The records of the 7000 patients with spinal cord paralysis admitted to

TABLE I

Pathology accounting for amputation in 83 patients with spinal cord paralysis

\begin{tabular}{|c|c|}
\hline Pathology & Number of Patients \\
\hline Trauma & 23 \\
\hline Pressure sores & 19 \\
\hline Infective conditions & 13 \\
\hline Atherosclerosis & I4 \\
\hline $\begin{array}{l}\text { Following aortic surgery for } \\
\text { atherosclerotic complications }\end{array}$ & I7 \\
\hline Deformity of limb & 4 \\
\hline Tumour & 3 \\
\hline Iatrogenic & 3 \\
\hline Obscure & I \\
\hline
\end{tabular}


the National Spinal Injuries Centre (N.S.I.C.) between 1944 and I98 I were reviewed. Eighty-three underwent major limb amputation, mainly because of trauma to the limb at the time of spinal injury, or the complications of pressure sores, or bone and joint infection (Table I). Histology was not available on some of the earlier patients who required a limb amputation because of pressure sores, but in the later patients where histology was available, no evidence of obliterative arterial disease was found. In I4 patients who had been paralysed for several years, amputation was performed for gangrene due to atherosclerosis. The clinical features and management of these patients are described.

A further three patients developed both spinal cord paralysis and gangrene of a lower limb following major aortic surgery, and will be discussed separately.

\section{Clinical Features}

\section{Sex distribution}

Twelve patients were male and two female.

\section{Age at onset of spinal cord paralysis and at amputation}

The average age of onset of the spinal cord paralysis was 40.8 years and at amputation 60.6 years. The time intervals between paralysis and amputation are depicted in Fig. I.

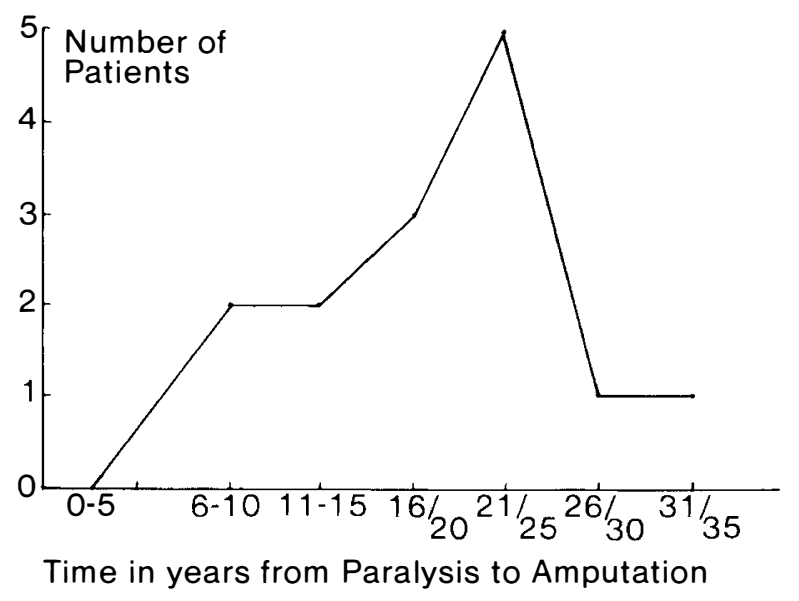

FIG. I

Relative time interval between onset of paralysis and amputation for peripheral vascular disease in 14 patients.

\section{Neurological lesion}

There were three patients with an incomplete tetraplegia, and I I with paraplegia, consisting of eight thoracic (seven complete and one incomplete) and three lumbar (complete) lesions. 


\section{Aetiology of the spinal cord paralysis}

The spinal cord paralysis was due to trauma in nine instances. In another four, paralysis was due to either a prolapsed intervertebral disc, glioma, spinal angioma or epidural abscess. In a further patient, paralysis occurred suddenly 8 months after a left hemicolectomy for carcinoma of the colon, when intra-abdominal sepsis was still present and spinal cord infarction due to atherosclerosis could not be excluded.

\section{Incidence of amputation}

Figure 2 shows the number of amputations performed over each 5-year period.

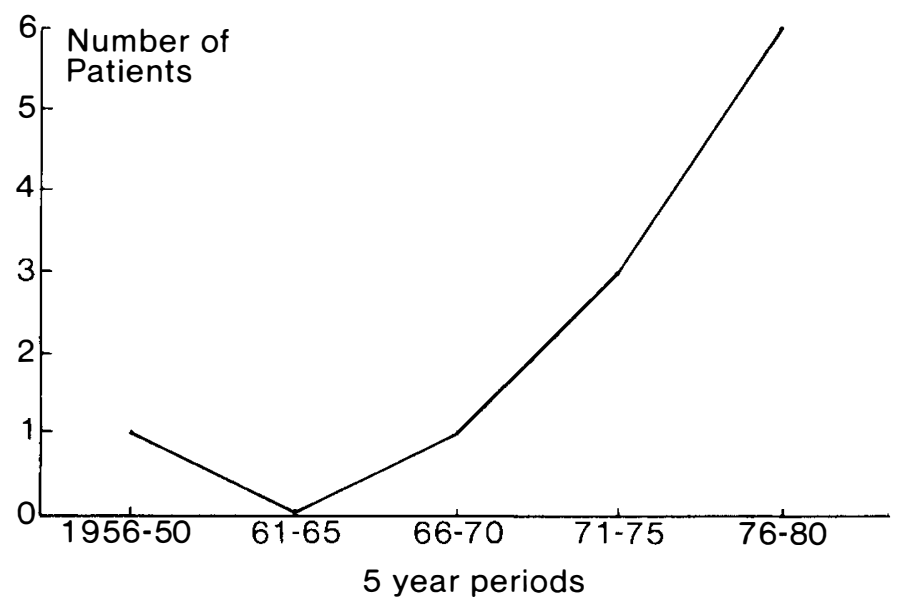

FIG. 2

Number of amputations for peripheral vascular disease in 14 patients over 5-year periods.

\section{Method of presentation}

This was as follows:

I. Gradual or rapid onset of gangrene- -9 patients.

2. Rest pain and later gangrene-I patient.

3. Pressure sore of foot, rapidly spreading with widespread tissue necrosis (Fig. 3)-3 patients.

4. Buerger's disease-I patient.

\section{Other evidence of atherosclerosis}

Three patients had previously had at least one myocardial infarction, and a further three showed post-mortem evidence of myocardial infarction. Of I 3 electrocardiographs studied, four showed evidence of previous myocardial infarction and a further three showed ischaemic changes. Six were normal. One patient had previously had a cerebrovascular accident. 


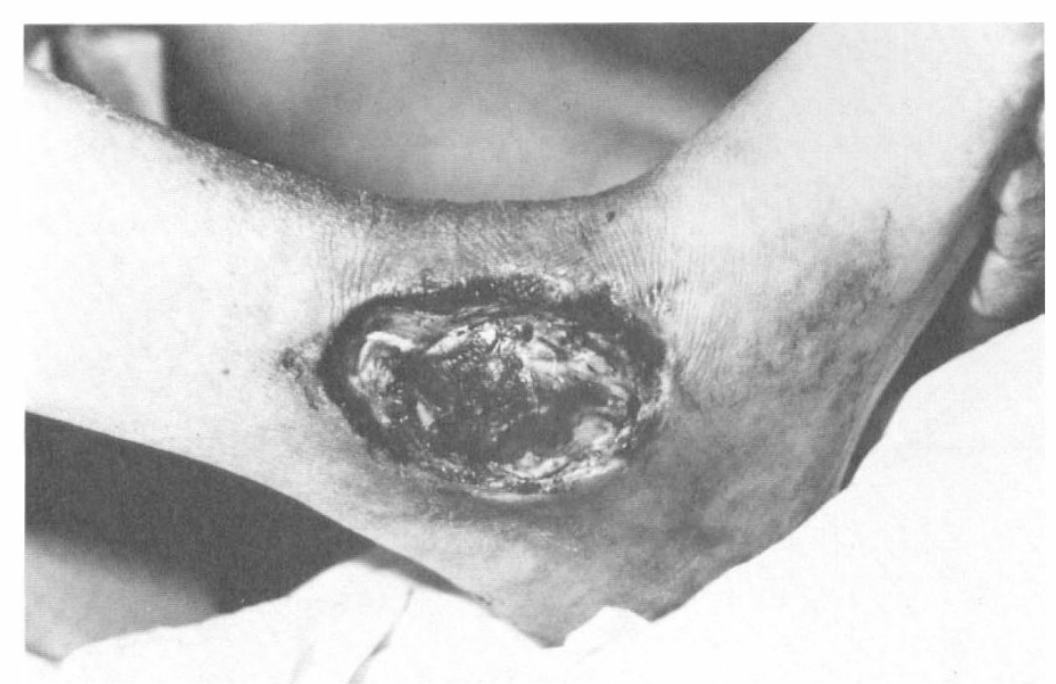

FIG. 3

Pressure sore over lateral malleolus, resulting in widespread tissue destruction.

\section{Possible factors contributing to atherosclerosis}

Smoking. Ten patients had been moderate to heavy smokers for many years. In four patients the smoking habits were not known. One had Buerger's disease (thromboangiitis obliterans).

Diabetes. This was present in one patient.

Hypertension. Five of the patients had a blood pressure consistently greater than $170 / 100 \mathrm{mmHg}$.

\section{Level of amputation}

Twelve patients underwent above-knee amputation and in four of these bilateral amputation was necessary. Two patients had a below-knee amputation.

\section{Io. Revision of amputation}

Five patients required revision. In two who had undergone amputation of one or more toes, an above-knee amputation became necessary. In a further two patients, a below-knee amputation required revision to an aboveknee amputation and in one patient an above-knee amputation stump required trimming.

\section{Prosthesis}

A prosthesis was satisfactorily fitted in two patients. Twelve did not have a prosthesis for the following reasons: 
I. Four patients died too soon after amputation for a prosthesis to be considered.

2. One patient was thought to be too old and frail; aged 73 years.

3. Two patients refused, because of the risk of pressure sores in the stump.

4. One patient had a severe flexion deformity of the hip joint.

5. The reasons were not known in four instances.

\section{Survival rate}

Seven patients died, with an average survival time of $\mathrm{I} \cdot 5$ years after amputation. Seven were still alive after an average of $2 \cdot 3$ years.

\section{Amputation Following Major Aortic Surgery}

Three male patients, with an average age of 58.5 years, became paraplegic (all had thoracic lesions) and developed gangrene of a lower limb following aortic surgery for atherosclerotic complications. This catastrophe followed aortic aneurysm resection in two patients (the aneurysm was ruptured in one) and insertion of an aortic bifurcation graft in another (Fig. 4).

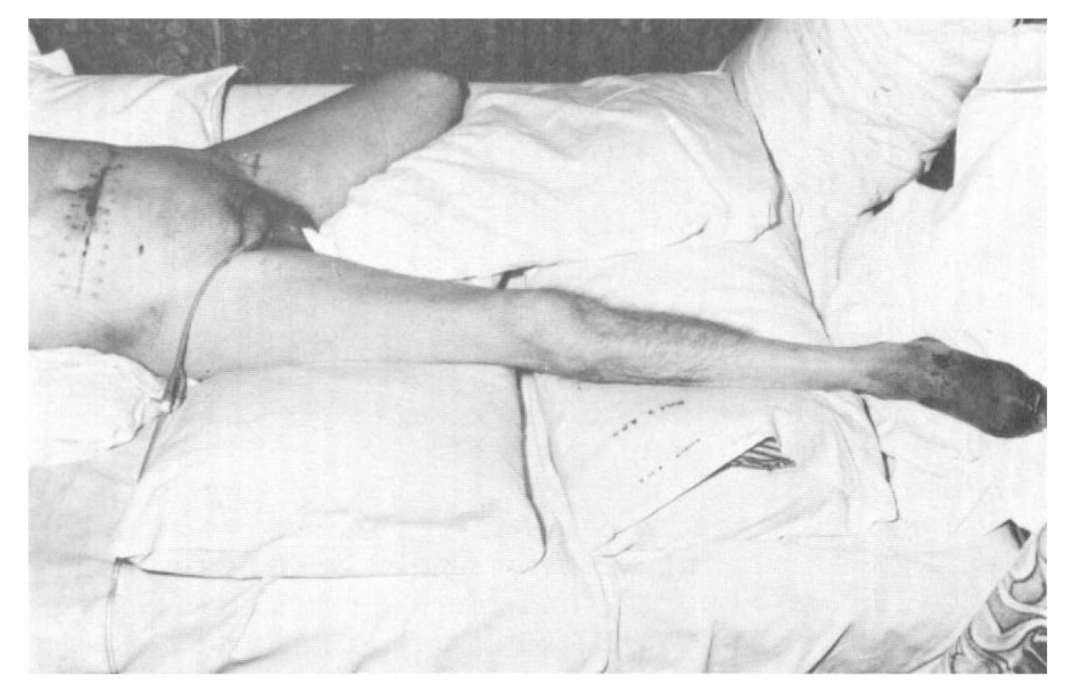

FIG. 4

Gangrene of lower limbs following aortic bifurcation graft for abdominal aortic aneurysm.

Two patients had a history of previous myocardial infarction, one of whom also had intermittent claudication (two of the three were heavy smokers but the smoking habit was not known in another. One was severely hypertensive). Above-knee amputation had to be performed, and in one patient a Syme's amputation was also necessary in the other limb. Two patients were alive after $I \cdot 8$ years and one died after 3.5 years. 


\section{Discussion}

Each year 5000 new lower limb amputees from the general population of England, Wales and Northern Ireland are referred to the Department of Health and Social Security Artificial Limb and Appliance Centres. Of these, around 3750 ( 75 per cent) have lost their limbs through peripheral vascular disease or diabetes (D.H.S.S. 1980). An unknown number are never referred, because of serious associated problems such as hemiparesis or severe cardiovascular disease.

The management of paraplegia has improved so much over the last 30-40 years, that more patients are surviving into the later years of life, a period when atherosclerosis and its complications are commonly seen in the general population. Whether paraplegia predisposes to the development of atherosclerosis cannot be stated from the study of the small number of patients in the present series. Nine patients with traumatic paraplegia developed atherosclerotic gangrene. Their average age of onset of paraplegia was 36.9 years, being later than the average age of onset of $3 \mathrm{I} \cdot 6$ years seen in a recent series of 335 patients with traumatic spinal cord paralysis admitted under one of the authors (J.R.S.). As the life expectancy of paraplegics is reduced it may well be that the patients who develop gangrene tend to be those who have become paralysed at a later age, younger patients not surviving long enough to develop this complication.

Hypertension and amyloid disease are commonly seen in paraplegia but the role played by hypertension in the pathogenesis of atherosclerosis is unproven, and there is no evidence that amyloid, present in three of the I4 patients, predisposes to atherosclerosis. Tribe (1969) found no increased incidence of coronary atheroma in autopsies on paraplegics over several years at the N.S.I.C.

The diagnosis of peripheral vascular disease in the paraplegic tends to be made late because, as the patient is usually largely confined to a wheelchair and has impaired sensation, symptoms of intermittent claudication will not appear. Similarly, rest pain cannot be appreciated in the paralysed limb. Thus patients with established atherosclerosis of the lower limb will tend to be asymptomatic until severe ischaemia or gangrene occurs, and it is too late to perform reconstructive surgery.

Approximately 50 per cent of patients in the general population who have an amputation for peripheral vascular disease die within 2 years, and half of the survivors lose the remaining lower limb (Dallas Brodie, 1970). Reviewing our figures, the overall amputation rate was I per I0000 of the spinal cord paralysed per year. Since 1975 the amputation rate for atherosclerosis has doubled, so that this condition now accounts for 38.5 per cent of all amputations performed at the N.S.I.C. Half of the patients died within I 5 years, a figure similar to that seen in the general population. Life expectancy is therefore very limited. Most patients are already greatly disabled before they undergo amputation. It is particularly important for the patient to return home as early as possible but the fitting of a prosthesis should be considered and at least discussed with the patient. The need for many patients to restore their 'wholeness' should not be under-estimated, even if they cannot walk. A few previously walking patients will be able to use a weight-bearing caliper but most will be eligible for a cosmetic prosthesis. 
As paraplegics are already disabled, they appear to adjust to the loss of a limb, which is often paralysed, more readily than the able-bodied. However, the seriousness of the procedure should not be under-estimated. With their improved prognosis, the paraplegic and tetraplegic population will become an increasingly ageing one and we must expect the various manifestations of peripheral vascular disease to present even more frequently in the future.

\section{RÉSUMÉ}

Les gangrenes des membres inferieurs dus aux maladies vasculaires peripherique chez les patients avec lesions de la moelle epinière sont revues.

La presentation de ces problemes et les difficultés diagnostiques au commencement de la maladie sont discuté.

L'incident de ces complications et le prognostique sont comparé avec la population non-paraplegique. Des indicateurs pour le treatement de cette complications croissante en apparence chez le para-tetraplegique vieillissant sont proposé.

\section{ZUSAMMENFASSUNG}

Die Komplikation mit einem brandigen unterm Bein durch peripherische gefässförmige Entzündung ist revidiert in dem Rückenmark gelähmten Patient.

Die Lehrweise der Stuation wird diskutiert und die Schwierigkeiten in der fruhzeitigen Diagnose der Krankheit wird Nachdruk gegeben. Die Umstände der Komplikation und ihre Prognose wird verglichen mit der in der allgemeinen Bevölkerung.

Anhaltspunkte in der Handlungsweise von diesen scheinbar zunehmenden Komplikationen bei älteren Rückenmark Männern werden gegeben.

\section{REFERENCES}

Department of Health and Social Security, Statistics and Research Division, (1979). Amputation Statistics for England, Wales and Northern Ireland.

Brodie, I. A. O. Dallas (1970). Lower limb amputation. B. F. Hosp. Med., 4, 596604 .

TRIBE, C. R. (1969). In: Tribe, C. R. and Silver, J. R. Renal failure in paraplegia, 98-99. Pitman Medical, London. 